Submitted to Journal of Social and Cultural Geography

(Dec 2007)

The Art and Craft of Train Travel ${ }^{1}$

Laura Watts

Department of Sociology, Lancaster University

Centre for Transport \& Society, University of the West of England

Contact:

I.j.watts@lancaster.ac.uk

tel/fax +44 (0)7092 201011

Department of Sociology

Bowland North

Lancaster University

Lancaster LA1 4YT

UK

\footnotetext{
${ }^{1}$ COPYRIGHT: This online draft script may be cited or briefly quoted in line with the usual academic conventions. You may also download it for your own personal use. This script may not be published elsewhere (e.g. mailing lists or bulletin boards) without the author's explicit permission. If you copy this script you must include this copyright note. This script must not be used for commercial purposes or gain in any way. You should observe the conventions of academic citation.
} 


\section{The Art and Craft of Train Travel}

Laura Watts

\section{Abstract}

Current theories concerning the social and material construction of time and space have little to say concerning the specific things and people involved. For example, how do times and spaces get made on a train - with passengers, train seats, tables, and views through the window? Through a travelogue of one train journey across England, this paper explores the art and craft of train travel, and the making of a particular time and space. The paper draws together science studies approaches to socio-material relations, and geographical concerns with socio-spatiality, to discuss passengers as spatially distributed persons and property. Reflecting on ethnographic evidence in the form of quotations and photographs woven through the text, it demonstrates how these heterogeneous passengers craft their travel times as an effect of their travel time use; how socio-material interactions with pens, papers, puzzles and electricity pylons make time. Following Michel Serres, it also suggests how passenger time is not a simple flow but a percolation, and how these passenger times coalesce in train carriages to form communities. The paper is itself a journey, in the form of words and images, which begins and ends with the imaginary, social, and material work of making a destination.

\section{Keywords}

Science Studies; Ethnography; Mobilities; Transport; Travel; Mobile Ethnography 


\section{I ntroduction}

Of all the modes of transport, the train is perhaps the best aid to thought: the views have none of the potential monotony of those on a ship or plane... at the end of hours of train-dreaming, we may feel we have been returned to ourselves - that is, brought back into contact with emotions and ideas of importance to us.

Alain de Botton, The Art of Travel

Train travel is not simply movement along a predetermined line, it is also an art, the art of train travel (Adler, 1989; de Botton, 2002).

Much recent theory across the social, cultural and geographical literatures has explored how time and space are an effect of socio-material practice, that there is an ongoing emergence of space and time through dynamic re-arrangements of social and material relations (e.g. Dodge and Kitchin, 2004; Massey, 2005; Thrift, 1996). Space and time are not a priori, nor fixed in some universal epistemology, but are effects of particular practices and performances (Gregson and Rose, 2000); so places are made differently, depending on what is done there and who does it, an Australian Aborigine makes a different place compared to an Australian settler, even though they may occupy the same geographical location (Verran, 1998). As Doreen Massey puts it, inspired by her train journey between Milton Keynes and London, 'as you travel you are part of the constant process of the making and breaking of links... of yourself, of London... of Milton Keynes, and thus of space itself' (Massey, 2005: 
118). But what particular activities and practices make space and time (Ingold, 2006)? How do the links between places get made and broken whilst onboard a train carriage? What specific social and material relations and arrangements are involved? There should be much to say concerning the arrangement of train seats, timetables, windows, tickets, newspapers, rain clouds, mobile phones, rucksacks, railway cuttings, and all the social and technological flotsam of train travel. Yet, there has been little (usually within wider discussions such as Letherby and Reynolds, 2005; Peters, 2006; Schivelbusch, 1987). As a train traveller, how am I and the things around me implicated in what has become a well-theorised crafting of time and space?

In writing of the crafting of train travel, I am also establishing a mnemonic for my attention to socio-material relations. Crafting is technical praxis, as derived from the Greek tekhne. It is the competent expression of a method; a skilled manipulation that transforms clay into pots, words into stories, glass into optical fibre, and voltmeters into a technical knowledges of train signalling (for a discussion of craft and method see Law, 2004). Crafting always involves the re-arrangement of social and material relations. Our knowledges, experiences, and perceptions of the world are woven and made in such ongoing crafted re-arrangements (Ingold, 2000a). Following this understanding of craft as technical skill, there is an art of train travel in the sense of a skilled artistry that creates experiences through social and material practice (Ingold, 2000b: 350). 
The format of this paper resembles a travelogue, a narrative journey down the west coast of England. Although perhaps similar to phenomenological accounts of moving through landscapes (e.g. Wylie, 2002) it differs in its methodological basis. Rather than observing movement through the world, its method is ethnographic: it involves a long-term participation in movement, whilst also attending to the shifting relations between people, things and places. Movement is inherent to ethnography. It is a matter of shifting locations, not simply in travelling between home and fieldsite (Clifford, 1997), but in a concern with the effect of this movement; acknowledging that an ethnographer is constantly working at shifting their relations in order to constitute an ongoing fieldsite (Gupta and Ferguson, 1997). A 'mobile ethnography' takes this further (Watts and Urry, in prep.), by travelling with, and constituting, a moving fieldsite; participating in the relations between things, people and places onthe-move (see also Laurier, 2004; Lee and Ingold, 2006). In this example, my craft, as ethnographer, was to work at making the fieldsite of a train journey.

As part of its own ongoing journey, the paper weaves together science studies approaches to socio-material relations, and geographical concerns with sociospatiality; it is explicitly interdisciplinary. This approach derives from a project concerned with Travel Time Use in the Information Age, which draws together transport studies, mobilities (Cresswell, 2006; Urry, 2000), as well as science studies, in a study of the practical and political configurations and possible reconfigurations of travel time use (LyonsJain and Holley, 2007; Lyons and Urry, 2005; Watts and Urry, in prep.). The mobile ethnography presented here is only one part of an extensive set of ethnographies conducted across the UK as part of the 
project, involving over 260 hours of travel time. The concepts and arguments derive from months travelling on other trains and services, including commuter trains, rural trains, and London-based services.

The points of departure for this paper are the field notebook quotations and photographs, taken whilst travelling on the same timetabled service, once a week for three successive weeks. The words and images act as evidence, and as a poetic evocation of the journey.

In some respects this paper is a detailed reflection on the everyday, on the banal moments of travel. But in so doing it weaves a story of how the mundane things of train travel participate in what are more usually abstract theories of space and time. Alongside other research concerned with objects on-the-move and their temporal and spatial effects (Bissell, 2007; Laurier, 2004; Laurier and Philo, 2003), this paper explores the missing masses of things (Latour, 1992) in the making of one particular moving space and time: a ten hour train journey across England, from the city of Lancaster in the north-west to the town of St. Ives in the far south-west, during July 2005.

\section{The J ourney}

[One morning in Lancaster] I am imagining sitting having breakfast besides a turquoise sea, beneath a warm summer sun. 
When does a train journey begin? As an ethnographer it began with negotiating access and permission from the train operating company. But it also began with imagining the journey, imagining some moment of arrival in sufficient clarity that I knew I would need to stay overnight near the final station-stop of Penzance; that there was the possibility that I might stay in the harbour town of St. Ives. I began to make the journey, and therefore began to travel, as I created the experience of an al fresco breakfast. This was not purely imaginary work in a Kantian mind, but was imaginary, social and material work: I had to make telephone calls to bed \& breakfast accommodation, pack an overnight bag, negotiate the train timetable, organise train tickets. In this work the journey began to take shape, possibilities for the future were both made and curtailed. The train journey was not simply unknown and infinite in possible extent until the moment I stepped onboard, it developed conditions of possibility established by the practices and knowledges I made before ever leaving the house. The journey began in the always social, material, and imaginary work of creating the destination.

I have packed my bags so that they are easy to store on a train, and easy to run with. A paperback novel is in the top, for those unexpected long moments of waiting... This field notebook and my camera are similarly accessible.

The space and time of the journey began in the carefully crafted work of preparation and planning. Yet, these moments were not continual but were temporally and spatially distributed. My train journey was not a seamless flow of times and spaces from departure to arrival, but was discontinuous. The journey was not even fitful, 
stopping and starting, it was only present in fleeting moments whilst I planned and imagined, packed a notebook and camera, otherwise it was absent. Similarly, Michel Serres suggests that time is not a laminar flow but turbulent, full of folds, mixes, and ruptures: 'Time does not always flow according to a line... nor according to a plan but, rather, according to an extraordinarily complex mixture, as though it reflected stopping points, ruptures, deep wells, chimneys of thunderous acceleration, rendings, gaps' (for a discussion of Serres' approach to time see Bingham and Thrift, 2000; Serres, 1995: 57). It's a theory of the flow of time that is chaotic rather than classically ordered, and where time is not contextual nor constructive of social action (e.g. Thrift, 1996); practice is not situated in time, but rather the reverse: time is an effect of situated social and material interaction or tasks (Ingold, 1995, 2000c). When driving a car, for example, the prehistoric past is folded in to the present through the use of the wheel, and the future is present through the dashboard display of the number of miles to the next service. Temporality is always local and variable, the shape of its flow changes as things and people interact differently (as Doreen Massey theorises at length with respect to space-time; Massey, 2005)..The temporality of my journey did not flow in a line, it percolated, as Serres would say (ibid: 58), drip, drip, dripping, as I picked up the phone to book the accommodation one day, wrote an email to ask for permission a week or so later, occasionally daydreamed of early morning mist and coffee. Some times I was on the journey. Some times I was not. Within this turbulent, juddering temporality, rather than an ongoing flow, the journey moved onwards. 
We depart at 12:48. Usual chaos as people attempt to put their luggage into place - particularly flight-cases, which never fit overhead so people have to sit with them in front of their knees... two women are waiting in the vestibule, sitting on their suitcases. I ask if they are going far, next stop they say with a smile.

[A woman boards and] puts her handbag on the seat by the window rummages in it for water, bottle, book... and keys - [which] go on to table and finally a phone, which she uses to text someone. She pulls out a wad of paper, print-out of a website, and starts to make short tick marks on it as she reads...

A woman smiles at me as she sits down. Puts her... sale bag next to her as she sits by a window. Then, with handbag on her lap, takes out a water bottle, an emotion magazine, and a number of Lundy Island flyers, one after another.

Bottle, novel, keys, phone, passengers do not only fill a train seat, they fill a seat, a table, often under the seat, the adjacent seat, as well as a luggage rack. Following ideas of distributed personhood (Gell, 1998), a passenger can be understood as both person and property; a person does not end at the skin but includes clothes, money, jewellery, and all the materials necessary for meaningful social interaction. When travelling by train, mobile phones, novels, and flight-cases are such prosthetics, they 
are part of the passenger and are meaningfully attached to them, although distributed in space. Both person and property travel together, and engage with the train journey as a single meaningful entity. Nothing of that distributed and heterogeneous passenger should be lost en route, or travel at a different speed, or take a different route.

Moreover, the distributed passenger is spatially configured: a rucksack is packed so that a notebook is ready to hand for long moments of waiting, the contents of a handbag is unpacked onto a fold down table. These are two particularly important configurations of the passenger, with their own particular qualities and resistances: the packed passenger and the unpacked passenger (see Figures 1 and 2). The packed passenger is configured for movement, for walking to the train station, for stepping through a carriage to a seat, for dashing on to a connecting service. Only a small number of items are to hand, everything else is compressed and packed away, and so there is little possibility for things to do. Packed passengers are highly mobile and equipped for waiting (Bissell, 2007; Gasparini, 1995). In contrast, unpacked passengers are a reconfiguration of person and property into a shape well-equipped for travelling. Things are placed to hand, on a table or on an adjacent seat for example; unpacked passengers take considerably more space than simply a body in a seat. Unpacking takes time and space, if the journey is too short or if there is not enough space to unpack into, then passengers have to remain packed, waiting in the vestibule for the next stop, perhaps bored (Anderson, 2004). Importantly, unpacked passengers are also relatively immobile. Their configuration includes and requires fixed tables, fixed seats, to place their things in and on; parts of the train carriage 
that do not move. Therefore they, too, become fixed in place, fixed in a seat; become part of the train carriage. In order to move to a different seat, or even to sample the buffet, these passengers have to take the time to reconfigure and detach themselves, to pack-up to some extent, as this example suggests:

[A man] stands up, he has large headphones on, sorts through his overhead belongings... moves a bag down to seat level.... [Twenty minutes later] he starts to pace at the far end of the carriage, hands in his jacket pockets, he tests his luggage in the rack, checks it will slide out easily. He pulls open a magazine and stands looking at it on a table... [Fifteen minutes later] he gets off the train with his bag and huge suitcase on wheels.

The woman opposite me gets up to check her case, she can't see it - it had fallen over. Different passengers keep their luggage on different lengths of leash.

\section{[INSERT FIGURE 2 FROM HERE]}

But an unpacked train traveller is a shape highly conducive to sudden and unexpected changes in local circumstances. They are a socio-technical species adapted to travel, a creature constituted by body and bags and belongings. ${ }^{(1)} \mathrm{A}$ welladapted unpacked passenger is easily able to translate half an hour in a rowdy carriage as exploits within a novel, or transform a delay at Crewe into a musical interlude on their music player. 
However, unpacked or packed, it is not the passenger who makes and breaks space, as Massey suggests, in the very practical sense that they do not participate in moving the train. The work of passengers does not involve driving the train, or laying the track, or creating the timetabling system. Their space is framed by a metal cage, a train carriage that holds together (and the consequences of the carriage breaking are very serious). Only from either a disembodied god-like location, or in an aeroplane over-head, or in the railway operations room which locates the train as it passes signals, can someone else perceive their movement in abstract space from Milton Keynes to London, or from Lancaster to St. Ives. This is not a denial of the changing landscapes of train travel but an acknowledgement of their specificity. Passengers asleep or travelling at night when there is nothing but blackness through the window, still move, still travel; space is still transformed because it's not the passengers that are doing that work. Bruno Latour, in his musings on the making of train times and spaces, argues that transportation is a matter of attending to the techniques of transformation; to the labours of making time and space, which are rather different for a man reading a newspaper on a TGV compared to a woman cutting through the undergrowth to create a path for a train (Latour, 1997). The former has little to do with getting the train from place to place, is physically unmarked by its passing, but the latter must endure considerable hardship and sweat to create that pathway. The making and breaking of space is the work of the railway engineers and designers who built and maintain the train infrastructure, who service the carriages at a depot, and the crew who drive the 
train and keep it on the tracks (for a similar argument with respect to ships see Law, 1986). If the engine or crew stop working, the train stops moving:

Introduce myself to the train manager, who is young and very friendly. He mutters 'they [the passengers] do some very strange things' [which is] seconded by the first class stewardess ... The manager tells me that it's all change at Birmingham New Street. Since the train only has one engine 'it won't get over the hills in Devon,' he says.

Many of those around me look out at the dotted mobile radio masts, the flood plains and town beyond, the dark watery sky and sun-brightened pylons... the power lines lit up, white arcs against the sky.

As I walk back and forth through the train people are beginning to recognise me, regard me with curiosity - my behaviour marks me ... I feel like I am a disruption, moving up and down the train, an irritation. It's hard to get passed everyone and their luggage. Hard not to knock elbows, trip over bags.

As an ethnographer I was neither a passenger nor a member of the train crew, my labours, what I did, were different and marked me out. I was not immobile like an unpacked passenger, nor was I responsible for the mobility of the train. I moved differently within the world of the train; I was doing something else. My crafting of train travel involved a different method, the deployment of different apparatus, different tools, in this case an ethnographic intervention into the making of space 
and time on-the-move. My work onboard created a different temporality to those around me, an ethnographic temporality I had to constantly work at. I had to continually work at locating myself as an ethnographer and resist shifting to the location of a passenger:

The window is sucking me outside the train, into the world beyond. The buildings, the river with its strange sunken wooden boat. Hard to look inside the carriage - I'm sucked out to daydream amongst the passing pylons.

I'm starting to grow tired... Outside the light seems to getting darker... Yellow dried-out grass, and cows. Small patches of woodland. It's growing darker, a storm.. [Now] it's raining hard outside... Feel rooted to my seat and table. I've sat here so long it seems hard to move.

By location I do not simply mean the reflexive, biographical, or positional difference between myself, passengers and crew (Rose, 1997). Rather that we are located in a particular, and always partial, situated knowledge (Haraway, 1991b). Train travel does not comprise a single, universal clock time through which passengers move in different ways. Although the scientific measurement of time, as measured by clocks and printed in timetables, is one very important time for the railways (Urry, 2007; Chapter 5) - clocks tell passengers and crew when to arrive at the station and when they might depart - it is not the only time. As Bruno Latour says of train times and spaces: 'we never encounter time and space, but a multiplicity of interactions... Nothing in the mind, nothing, but a lot of know-how of those who, by clever 
technical action, can weave together [heterogeneous] actants that were incommensurable a minute before' (Latour, 1997). Times and spaces are not subjective nor socially constructed but are made and experienced in socio-material interaction. These interactions produce an ontology, as much as they create a geography - they make the world. In these different locations, different times and spaces are made:

14:19 A man and woman who boarded at Birmingham New Street are both doing sudoku [puzzles]... She has a magazine open and on top of it a sheet of sudoku... In front of her the businessman (with jacket hung up) has elbows on the newspaper and is deep into the [puzzle].... He is enthralled... doing the difficult one - half way through. Leans back for a while, then leans in, head in his hands... Neither has looked up for the entire journey, despite the sun beginning to flicker through tree and cloud.

15:10 The man leans back, takes his glasses off, folds his arms... picks up his mobile, dials... leans over the puzzle and newspaper and starts again.

15:21 The business woman stops, puts her sudoku in her bag and opens up her magazine... The businessman... is still enthralled. He picks up his pen, ready to mark.

15:24 [The businessman's] glasses go on again, elbows back to the table, eyes down hard. 
15:29 Bristol Parkway. The sudoku is put away... A grey cloud hangs over Bristol as we pull in.

These two travellers fly along down the train line immersed in their world of sudoku puzzles. As I write frantically in my notebook, their bodies barely shift during an hour of almost suspended animation; pens poised, eyes intent on the page. Their time is not my time, their world is not my world. I am writing, watching, glancing, the journey almost too fast to capture with ink. Our travel times are not shared but situated in our differently paced practices: puzzle time and ethnography time. Our times are not relative, there is no temporal comparison possible between our worlds (I cannot say how fast they experience their time). Rather we craft our travel time differently using different artefacts, different practices, different methods. My ethnography time involves working at writing, engaging, theorising with pen and paper. Their time involves working with puzzle and pen, calculating, contemplating, writing numbers. Different practices create different times. My ethnographic time is rapid, compressed compared to the passing of minutes on my watch. It is compressed, in part, through my writing fieldnotes, and in part through my engagement with their bodies, pens, and puzzles. This is not some expression of time-space compression or the annihilation of space and time due to speed (Stein, 2001), such compression is an effect of the work of measuring and comparing a clock time and Cartesian space. That is not the work ongoing here. It is more prosaic, but no less important. Both passengers and myself are making travel time, making an experience of time passing. But we are making it differently as an effect 
of our different locations and practices. As Latour suggests, you do not encounter time, you only encounter interaction - you look at a station clock, sleep through an alarm, have no sense of minutes passing whilst reading a good book. Ingold resonates with this in his study of how time is made by train drivers in contrast to rail industry measurements of their time: 'time is intrinsic to tasks' (Ingold, 1995: 9). ${ }^{(2)}$ It is in what we do that we experience the passage of time, so that measuring labour does not create the same temporality as doing the labour.

Here is the work of the passenger. It is not making and breaking train space, it is making and breaking train time; passengers work to craft travel time. And it is done in all the myriad of activities that passengers engage in when on-the-move. Passengers are not passive, they are always active, even if they are bored (Anderson, 2004). Even sleeping creates a particular temporality, rarely is it as simple as sleeping from the moment of boarding to the moment when the train pulls in to the station - there remain moments of social and material interaction:

At the table behind me a man lies back asleep or eyes closed, a set of keys, glasses, and magazine lying in front of him [on the table].... A woman who was asleep wakes and shifts, unwraps a boiled sweet from her handbag [and] stares out of the window... [She falls asleep again until] her mobile phone goes, loud and jaunty. It wakes up the sleeping man, who looks around, rearranges his limbs, and goes back to sleep... Exeter. The sleeping man wakes, grabs his keys and puts on his glasses, leaves with his bag. 
This is not a time versus space argument. Passengers are also spatially active in their reconfigurations of person and property (mobile phone, boiled sweets, handbag, keys, glasses, and so on) and in their interaction with the train space (seats and tables) as I have already shown. It is this spatial configuration which affects the possible interactions, the possible activities, and therefore the possible temporality. If you are standing, it's hard to sleep; unpacking and setting up a laptop computer often takes more room than its moniker suggests. Simply, travel time is made in travel time use.

\section{[INSERT FIGURE 3 FROM HERE]}

We are rolling past the sea [the English Channel]. I am curious to see how many people watch, surprised at how few [do so]. Many are ensconced with books, do not look up.

Opposite a man is reading a book intently, fist to forehead... The echo of a heavy electric guitar riff from someone's headphones pours over me... Diagonally across is a young woman... using her mobile phone and taking pictures of herself. She has huge nails... [She] has stopped playing with her phone and is now filing her nails with a large purple nail file... The man opposite looks up from his book at the nail file... eek, eek [goes the file]. He winces, looks slightly ill as the flakes fall... He covers his eyes with his hand, shielding them from the rest of the carriage. 
The multiple travel times made by passengers in their reading, nail filing, listening to music, writing fieldnotes, are not isolated flows but are proximate. Passenger flows of time coalesce for a moment, disperse in another moment. This returns to Serres' approach to time as a chaotic flux (Serres, 1995): passenger times are not laminar and separate, but may be twisted and mixed. The passenger, as a spatially dispersed configuration of things, interacts with a social and material world that has its own resistances - that kicks back. ${ }^{(3)}$ The passing pylons drew me out of my work in the train carriage, and kicked-back at my location as an ethnographer. I could not evade listening to the music from someone else's headphones. The man reading was infected by the flakes falling from the woman's nails. He could not ignore them, they kicked him out of his novel so severely that he then covered his eyes to avoid a further distraction. The sensoriality of train travel has affects (Rodaway, 1994); scents and sounds (and even cells) that spill out from passengers fill the space and interact in unanticipated ways. Travelling by train is filled with such moments, when the sensory materiality of a person, thing, or place, kicks-back ontically. But since it is in such interactions that time gets made, then these sensuous interactions can have affects on temporality. As passengers sensorially interact with each other, with things through the window, their times coalesce, mix, and are altered. Two people listen to the same music, where before one was writing fieldnotes. Two people watch a manicure, where before one was reading a novel. Quiet coaches onboard trains are a classic and obvious example of a place designed to reduce these sensory infections, particularly from mobile phone ringtones and conversations. Another, more subtle effect of the mixing of passenger times, and how they can flow together is in train carriages as places: 
Remember that the next coach down is the chatty social coach. This is the single and young children carriage. [Here] few people are in conversation.

[As I wander through the carriage] phones ring, people are laughing, a man is trying to conduct a phone conversation using a headset... In the Quiet Coach it is cold and quiet... pleasant after the screams and laughs of Coach D. Many people are reading [in here]...

And it is cold in this carriage [a difference in the air-conditioning], freezing, and full of rubbish: used coke bottles, newspapers torn on the floor, plastic bags.

Train carriages contain passengers and separate them into groups of persons and things. Passengers tend to remain within the bounds of a single carriage, rarely does a person's property become distributed over several carriages (although this is more common for cyclists). As the travel time of passengers mix through sensory interaction, so the temporality of passengers within a carriage begins to coalesce. The temporality of a train carriage becomes a shared experience, and individual passengers become more of a community. So, although there may be a single train moving down the tracks, there may be several communities of train travellers: one carriage is chatty, another is filled with phone calls, another is cold and still, another has few people but a collection of rubbish. The crafting of train travel rarely occurs in isolation, it is often intensely social (as well as material). Where the sensory 
materiality of passengers is in contact, time also seeps into contact: people strike up conversation in a socially vibrant carriage, sleep in a carriage that is still and quiet. To resist that, to craft travel times into dispersed flows, or sieve time as Serres puts it (Serres, 1995: 58), requires a mesh to separate those seeping interactions, and resist any mixing. Hence the popularity of music players with headphones, and notices by transport operators asking passengers not to bring pungent foods onboard, these are all meshes that attempt to sieve passenger time. Simply resisting that capillary action, which draws passenger times together into a twisted, braided flux, is hard work:

Nothing is happening in this carriage... Time and place here are static and unchanging. No one is doing anything - barely moving - as if in cryogenic freeze or stasis...

Nothing seems to happen... I want to write that something happens. But nothing happens. A man reads a book, then reads a newspaper. A woman fidgets and sniffs... A cloud catches me and I drift off, dreaming of my destination... I am drifting into reverie, the flashing light, the tiredness, the endless munching of crisps from nearby, the reading, reading... the juddering, the rolling of the carriage, the white light of Cornwall. I am travelling outside the train, through the fields, as though the carriage were air on which I was carried, blown along... 
I was becoming tired. In the carriage, time seemed to stretch and stretch, as activity and movement withered into near stillness. My resistance to this steadily gathering weight of time was failing. There was almost a heaviness from so many times drawing together, a pressurised flow from those around me, pressing insistently against my own temporality. I felt this slow, almost viscous time of the surrounding passengers as I wrote about their reading, fidgeting, munching. My time, as an ethnographer attempting to write and work at a fieldsite, was being altered. I was being translated from an ethnographer into a passenger. My craft was changing from making a fieldsite into simply making travel time as another passenger; my words capturing the translation as I drifted off into reverie, and became blown along down the train line.

[Change on to the] St. Ives train at 8pm. Train has sand everywhere - on seats, on the floor. People in flip-flops with red [sun-burned] faces getting off.

So when did my crafting of this journey finally end? As I stepped from the St. Ives train? As I crossed the threshold of my white-washed bed and breakfast? When I awoke the next morning? The crafting of travel time must surely end as it began, with the social, material and imaginary work of making a destination. Arrival is when there is no further to go, no further rearrangements necessary, no more sociomaterial and imaginary work to do; and the destination, as it has been negotiated over perhaps many weeks, becomes an experience, and then a memory: 
It is 9:30am. I'm sitting outside a café, warm beneath a white disc of sun covered by hazy cloud; watching the water slowly slide down the harbour, beaching boats one by one. Around me people wait for their breakfast. A baker turns up, leaps out of his van with a massive tray of warm loaves, and swings past with apologies. The [malted scent] of freshly-baked bread spills into the air as I write.

The art and craft of train travel is not simply an abstract or theoretical making of space and time. It is skilled and tiring work, which manipulates and is manipulated by an irrepressibly social and material world to create a moving experience - always both a translation in affect as well as place. There is a technical artistry to train travel, for mundane everyday things, the seats, our belongings, the passing views, can be woven together with bored repetition, or into train-dreaming (de Botton, 2002). And so the next part of our research passed on this art and craft of train travel, in the form of a 'travel remedy kit' designed to transform passenger experiences of travel time across many other, quite different, journeys, (Lyons and Watts, in prep).

\section{Acknowledgements}

Considerable thanks to Virgin Trains for permission to conduct the research, complimentary tickets, and to the many staff and passengers who helped the ethnography in so many ways. Thanks also to my colleagues on the Travel Time Use in the Information Age research project: John Urry, Glenn Lyons, Juliet Jain, and 
David Holley. I am very grateful to Sven Kesselring for inviting me to perform the original video-based version of this paper at the Cosmobilities network meeting, and also to Mark Whitehead and Deborah Dixon for providing me with the opportunity to translate that performance into this written text.

\section{Endnotes}

1. By speaking of a socio-technical species I am alluding to Donna Haraway's work on the cyborg, a hybrid social and technical creature, a mixture of both human and nonhuman, which she cites as one particular and important companion species (Haraway, 1991a).

2. Note that Ingold and Latour, although resonant in their socio-material approach to the creation of time, derive from distinct, and not always compatible, theoretical resources. For example, Ingold derives his approach to temporality from a Heideggerian dwelling perspective, and argues against unmarked space, and for place as always lived (Ingold, 2000c). In contrast, Latour argues that there is no lived place in contrast to abstract space, but that places and spaces are both effects of interaction: from walking aside a lake, to using rulers and a theodolite to create an abstract measurement of the lake (Latour, 1997).

3. In her work on the ontic role of scientific apparatus, Karen Barad argues for an agential realism: that there is a material world which kicks-back as we interact with it, and so makes a difference to how (and what) knowledge is made (Barad, 2007). 


\section{Captions}

Figure 1

Packed passengers travelling through Preston (around twenty minutes from Lancaster) @ L Watts 2005

Figure 2

Unpacked passengers and an ethnographer travelling towards Bristol (around three hours from Lancaster) (C) L Watts 2005

Figure 3

Viscous time within the carriage travelling through Exeter and Plymouth (around six hours from Lancaster) (c) L Watts 2005

\section{Bibliography}

Adler, J. (1989) Travel as Performed Art. American Journal of Sociology 94: 13661391.

Anderson, B. (2004) Time-Stilled Space-Slowed: How Boredom Matters. Geoforum 35: 739-754.

Barad, K. (2007) Meeting the Universe Halfway: Quantum Physics and the Entanglement of Matter and Meaning. Duke University Press. 
Bingham, N. and Thrift N. (2000) Some New Instructions for Travellers: The Geography of Bruno Latour and Michel Serres, in Crang, M. and Thrift, N. (eds.) Thinking Space. London, Routledge.

Bissell, D. (2007) Animating Suspension: Waiting for Mobilities. Mobilities 2: 277298.

Clifford, J. (1997) Routes: Travel and Translation in the Late Twentieth Century. London/Cambridge MA, Harvard University Press.

Cresswell, T. (2006) On the Move: Mobility in the Modern Western World. London, Routledge.

De Botton, A. (2002) The Art of Travel. London, Penguin.

Dodge, M. and Kitchin R. (2004) Flying through Code/Space: The Real Virtuality of Air Travel. Environment and Planning A 36: 195-211.

Gasparini, G. (1995) On Waiting. Time and Society 4: 29-45.

Gell, A. (1998) Art and Agency: An Anthropological Theory. Oxford, Clarendon Press.

Gregson, N. and Rose G. (2000) Taking Butler Elsewhere: Performativities, Spatialities, Subjectivities. Environment and Planning D: Society and Space 18: 433-452.

Gupta, A. and Ferguson J. (1997) Anthropological Locations: Boundaries and Grounds of a Field Science. Berkeley, University of California Press.

Haraway, D. (1991a) A Cyborg Manifesto: Science, Technology, and SocialistFeminism in the Late Twentieth-Century, Simians, Cyborgs, and Women: The Reinvention of Nature. London, Free Association Books. 
Haraway, D. (1991b) Situated Knowledges: The Science Question in Feminism and the Privaledge of Partial Perspective, Simians, Cyborgs and Women: The Reinvention of Nature. London, Free Association Books.

Ingold, T. (1995) Work, Time and Industry. Time and Society 4: 5-28.

Ingold, T. (2000a) Making Culture and Weaving the World, in Graves-Brown, P. M. (ed.) Matter, Materiality and Modern Culture. London, Routledge.

Ingold, T. (2000b) Of String Bags and Bird's Nests: Skill and the Construction of Artefacts, in Ingold, T. (ed.) The Perception of the Environment: Essays in Livelihood, Dwelling and Skill. London, Routledge.

Ingold, T. (2000c) The Temporality of the Landscape, The Perception of the Environment: Essays in Livelihood, Dwelling and Skill. Londond, Routledge. Ingold, T. (2006) Review: Doreen Massey, for Space. Journal of Historical Geography 32: 871-903.

Latour, B. (1992) Where Are the Missing Masses? The Sociology of a Few Mundane Artifacts, in Bijker, W. E. and Law, J. (eds.) Shaping Technology/Building Society: Studies in Sociotechnical Change. Cambridge MA, MIT Press.

Latour, B. (1997) Trains of Thought: Piaget, Formalism and the Fifth Dimension? Common Knowledge 6: 170-191.

Laurier, E. (2004) Doing Office Work on the Motorway. Theory, Culture and Society. 21: 261-277.

Laurier, E. and Philo C. (2003) The Region in the Boot: Mobilising Lone Subjects and Multiple Objects. Environment and Planning D: Society and Space 21: 85-106. 
Law, J. (1986) On the Methods of Long Distance Control: Vessels, Navigation and the Portuguese Route to India, in Law, J. (ed.) Power, Action and Belief: $A$ New Sociology of Knowledge. London, Routledge.

Law, J. (2004) After Method: Mess in Social Science Research. London, Routledge. Lee, J. and Ingold T. (2006) Fieldwork on Foot: Perceiving, Routing, Socialising, in Coleman, S. and Collins, P. (eds.) Locating the Field: Space, Place and Context in Anthropology. Oxford, ASA Monograph, Berg.

Letherby, G. and Reynolds G. (2005) Train Tracks: Work, Play and Politics on the Railways. Oxford and New York, Berg.

Lyons, G., Jain J. and Holley D. (2007) The Use of Travel Time by Rail Passengers in Great Britain. Transportation Research Part A 41: 107-120.

Lyons, G. and Urry J. (2005) Travel Time Use in the Information Age. Transportation Research Part A 39: 257-276.

Lyons, G. and Watts L. (in prep) The Travel Remedy Kit.

Massey, D. (2005) For Space. London, Sage.

Peters, P. F. (2006) Time, Innovation and Mobilities: Travel in Technological Cultures. London, Routledge.

Rodaway, P. (1994) Sensuous Geographies: Body, Sense, and Place. London, Routledge.

Rose, G. (1997) Situating Knowledges: Positionality, Reflexivities and Other Tactics. Progress in Human Geography 21: 305-320.

Schivelbusch, W. (1987) The Railway Journey: The Industrialization and Perception of Time and Space. Berkeley CA, University of California Press. 
Serres, M. (1995) Michel Serres with Bruno Latour: Conversations on Science, Culture and Time. Michigan, Ann Arbor, University of Michigan Press.

Stein, J. (2001) Reflections on Time, Time-Space Compression and Technology in the Nineteenth Century, in May, J. and Thrift, N. (eds.) Timespace: Geographies of Temporality. London, Routledge.

Thrift, N. (1996) Spatial Formations. London, Sage.

Urry, J. (2000) Sociology Beyond Societies: Mobilities for the Twenty-First Century. London, Routledge.

Urry, J. (2007) Mobilities. Cambridge, Polity Press.

Verran, H. (1998) Re-Imagining Land Ownership in Australia. Postcolonial studies 1: 237-254.

Watts, L. and Urry J. (in prep.) Moving Methods, Travelling Times. Environment and Planning D: Society and Space.

Wylie, J. (2002) An Essay on Ascending Glastonbury Tor. Geoforum 33: 441-454. 